\title{
Partial Pituitary Ablation with Implants of Gold-198 and Yttrium-90 for Acromegaly
}

\author{
M. HARTOG,* B.M., M.R.C.P. ; F. DOYLE, $†$ M.B., B.SC., F.F.R., D.M.R.D. ; \\ RUSSELL FRASER, * M.D., F.R.C.P. ; G. F. JOPLIN,* M.B., M.R.C.P.
}

Brit. med. F., 1965, 2, 396-398

The ideal method for the treatment of acromegaly remains uncertain. Evidence of local pressure from a pituitary tumour offers an absolute indication for treatment, and this has usually been surgical decompression; however, when treatment has been given by external deep $x$-ray therapy the majority of such patients have shown improvement in their visual-field defects (Fraser and Joplin, 1961). Where the presenting syndrome comprises only acromegaly and the other effects of excessive growth-hormone secretion the need for treatment may seem less obvious. The activity of acromegaly is difficult to assess, and the natural history of the untreated disease is not adequately known. Bishop and Briggs (1958) reported that $80 \%$ of their patients had died by the age of 60 predominantly from cardiovascular complications, but this high mortality rate awaits confirmation. Acromegaly without symptoms of a pituitary tumour has often been left untreated; however, we have implanted such cases as well as those with tumour signs or symptoms, so long as no evidence was found of any considerable extrasellar extension.

Acromegaly has in the past been treated by surgical removal of the tumour or by external deep $x$-ray therapy, and, more recently, by heavy-particle irradiation (Lawrence et al., 1962). As an alternative to these methods we have used needle implantation of radioactive seeds, with the intention of delivering a heavier dose of irradiation to the pituitary than is feasible by external deep $x$-ray therapy: the objective is the destruction of the overactive growth-hormone-secreting cells while not impairing normal pituitary function. To supplement the preliminary results of such treatment (Joplin et al., 1961b) this paper reports our more extended experience, and also our assessment of the relative usefulness of several parameters for the assessment of the activity of acromegaly.

\section{Subjects Treated}

Twenty-eight patients have been treated by implantation. These consisted of all the subjects recently referred in whom the clinical picture (Table I) and tests (Table II) clearly indicated acromegaly. The patients have been readmitted at approximately three months after operation for clinical reassessment and repeat of the investigations, and thereafter were followed in the out-patient department with occasional readmissions. If the response has not been satisfactory a second implant has been recommended. Nine patients have had second operations ; in none was the second implant done in less than four months after the first one.

\section{Tests of the Activity of Acromegaly}

These have all been indirect tests of growth-hormone hypersecretion, as direct assays of serum growth hormone have only recently become available.

The augmented insulin-tolerance test (Fraser et al., 1962). In this test a dose of 11.1 units/sq. metre body surface of soluble insulin is given intravenously; an "insulin resistance index" is obtained from the sum of the values (in $\mathrm{mg} . / 100 \mathrm{ml}$.) for the blood sugar at 60,90, and 120 minutes, for which the upper limit of the normal range is 142 .

The prednisone glycosuria test (Joplin et al., 1961a), which defines "pre-diabetic" subjects as subjects with normal oral glucose-tolerance tests who, after a total prednisone load of $60 \mathrm{mg}$., excrete excessive sugar in the 10 p.m. to 6 a.m. overnight urine (over $60 \mathrm{mg}$./hr. by the titration method), and/or show high midnight blood-sugar concentrations (at 12 midnight and 1 a.m., mean of over $128 \mathrm{mg} . / 100 \mathrm{ml}$.).

Other evidence of the activity of the disease was derived from serial photographs of the facies, hand volumes (by immersion in water up to tattoo marks at the wrists), the cortical thickness of the metacarpals as measured on a hand $x$-ray film, and the 24-hour urine calcium while on a diet containing under $500 \mathrm{mg}$. calcium/day.

\section{Implantation Technique}

The main features of the technique have been described (Joplin et al., 1961b). In most cases the transethmoidal route was used, but occasionally the transnasal route was preferred, depending on the shape of the pituitary tumour. The procedure was controlled by fluoroscopy with an image intensifier in the lateral and occipito-frontal planes, and the seeds were impanted on each side of the pituitary fossa. In five of the patients pituitary cysts were encountered at operation; these were recognizable by fluid coming from the implant needle just before insertion of the seed, or by a seed seen to fall after implantation.

\section{Irradiation Dose}

From the available evidence of the cumulative dose of external deep $x$-ray therapy which could be delivered to the pituitary without damage to the surrounding structures (Kelly et al., 1951 ; Buys and Kerns, 1957), and from our experience with total pituitary ablation for disseminated breast cancer that a dose of at least 100,000 rads was required to destroy pituitary tissue, it was decided to use a dose giving 10,000 rads to the periphery of the gland, which is thus less than a tenth of the dose we use for a total pituitary ablation. In the initial series (Joplin et al., 1961b) grains of the gamma-emitting ${ }^{198} \mathrm{Au}$ were used in the hope that the diffuse penetrating irradiation produced by this source would ensure irradiation of all parts of the pituitary without causing excessive necrosis. Later, when it became clear that a greater amount of irradiation was required, combined implants of ${ }^{198} \mathrm{Au}$ and ${ }^{90} \mathrm{Y}$ were used, giving the same peripheral dose but with half planned to come from each source. ${ }^{90} \mathrm{Y}$ emits beta rays of high energy, so the intense local necrosis would destroy the centre of the pituitary, yet without incurring any greater risk of damage to the surrounding structures, because the peripheral dose was

* Department of Medicine, Postgraduate Medical School of London † Department of Radiology, Postgraduate Medical School of London. 
unchanged. Recently the dose has been increased again, and ${ }^{90} \mathrm{Y}$ alone is being implanted with a planned peripheral dose of 20,000 rads.

The dose plans for the nine patients who had reimplants were decided for various reasons as follows: six implants of ${ }^{90} \mathrm{Y}$ alone, four with planned peripheral doses of 100,000 rads, one of 10,000 rads, and one of 1,000 rads. Three patients had mixed implants of ${ }^{198} \mathrm{Au}$ and ${ }^{90} \mathrm{Y}$, with a planned total peripheral dose of 10,000 rads, half being contributed from each source.

\section{Results}

\section{Preimplant State}

Table I shows some of the clinical features of 28 patients who were subsequently implanted. Only two had field defects ; one defect was a slight bitemporal hemianopia, and the other was a unilateral central scotoma due to a macular degeneration and unrelated to the acromegaly.

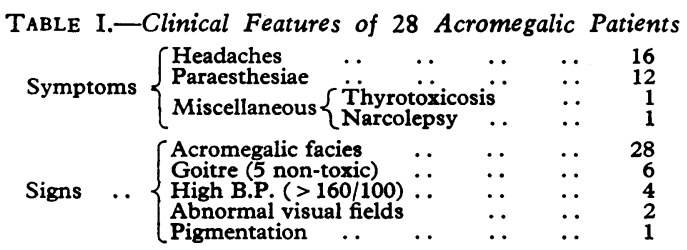

The results of the investigations done on these patients are shown in Table II. It will be seen that half of those tested were diabetic or "pre-diabetic" by the criterion of an abnormal prednisone glycosuria test. The great majority were insulinresistant, the values of "the insulin-resistance index" for the two exceptions being borderline (134 and 136). Half of those tested had a raised urinary calcium level, but only four had a raised serum-inorganic-phosphate level. There was one patient whose pituitary fossa was not recognizably abnormal on $x$-ray examination. In the remainder the abnormality was visible on the plain lateral and antero-posterior views of the fossa ; the most usual abnormality was an enlargement of the fossa, often with a double contour, indicating this enlargement to be asymmetrical. Lateral tomography, performed for the purpose of exact planning of the implant, defined these abnormalities more precisely.

TABLE II.-Test Abnormalities in 28 Acromegalic Patients

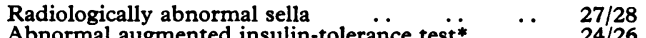
Abnormal augmented insulin-tolerance test ${ }^{*} \quad \ldots \quad 24 / 26$ $\left\{\begin{array}{llll}\text { Abnormal glucose-tolerance test } † & \ldots & \ldots & 7 / 28 \\ \text { Abnormal prednisone glycosuria test } \ddagger & \ldots & \ldots & 9 / 18\end{array}\right.$

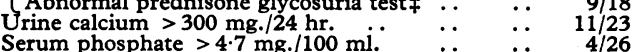

* Sum of blood sugar at $60,90,120$ minutes $>142$.

+ Five had clinical diabetes.

$\ddagger$ Mean midnight and $1 \mathrm{a} . \mathrm{m}$. blood sugar $>128 \mathrm{mg} . / 100 \mathrm{ml}$. and/or overnight glycosuria $>60 \mathrm{mg}$. $/ \mathrm{hr}$.

\section{Results of Implantation}

Overall results.-Twenty-two patients have been reassessed, the results being shown in Table III. The mean follow-up period was 19 months, and all except five have been followed for periods of more than six months. A " satisfactory response" has been defined as the loss of symptoms, along with recognizable regression of the acromegalic facies, a normal augmented insulin-tolerance test, and either a normal glucose-tolerance test or a pronounced amelioration in the diabetes of a patient who had been frankly diabetic before operation. Of the 22 patients assessed after their final implant 13 had satisfactory remissions, six a partial response, and three have been unchanged. There has been no instance of relapse after an initial improvement in either symptoms or the test abnormalities.

Clinical Changes Noted.-There is usually a striking diminution of soft-tissue overgrowth. We have studied this in the hands by making serial measurements of hand volumes. A change of more than $50 \mathrm{ml}$. in the volume of both hands has been found to be significant. Four of the patients with a satisfactory response showed a fall of over $50 \mathrm{ml}$. in their hand volumes. On the whole, however, this measurement has proved to be an insensitive index, as some patients have volunteered that their rings were looser on their fingers in the absence of significant change of hand volumes. Another change which has been noted has been the reduction in the width of the cortex of the metacarpal bones as measured by $x$-ray films of the hands. Four patients showed such changes out of eight who had sustained satisfactory responses and who had serial measurements made of hand $x$-ray films covering at least 18 months. Further, one woman with deep pigmentation lost this pigmentation after operation, while another who had attacks of narcolepsy became almost free of these. The patient with thyrotoxicosis had a satisfactory remission of the acromegaly after two implantations, but the thyroid state remained unchanged and she subsequently required radioiodine therapy.

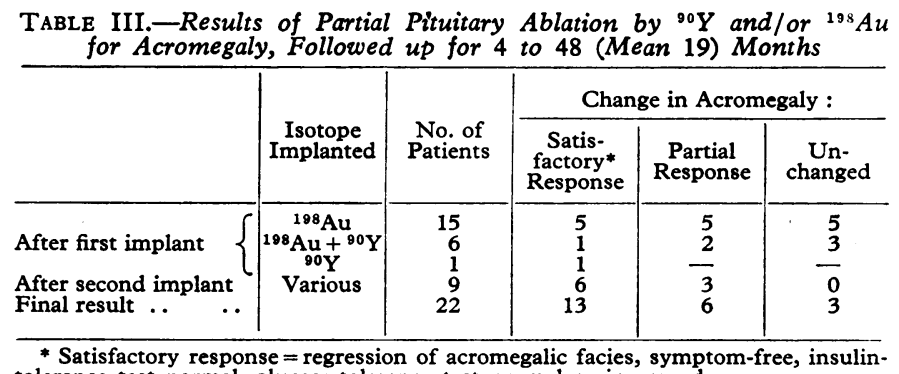

* Satisfactory response $=$ regression of acromegalic facies, symptom
tolerance test normal, glucose-tolerance test normal or improved.

Effect on pituitary function.-Table IV shows the state of the other functions of the pituitary after the final implantation in the 22 patients. With regard to menstruation, one woman who had had no periods for 12 months resumed regular periods after operation, three who were menstruating regularly before operation continued unchanged, while two others developed amenorrhoea. Of these latter, one was a woman aged 47 whose periods stopped after the first implant, while the other had had a second implant deliberately planned to ablate the pituitary. Seven patients required thyroxine and corticosteroid maintenance therapy: in two this was a sequel of a second implant designed to destroy the pituitary, and in five of infection in the pituitary after operation. In addition, there were two patients in whom neither of these factors existed yet who became steroid-dependent two and three years after operation.

\begin{tabular}{|c|c|c|c|c|}
\hline \multicolumn{3}{|c|}{ Menstruation } & \multicolumn{2}{|c|}{ Maintenance Therapy Required } \\
\hline Restored & Unchanged & Ceased & Thyroxine & Corticosteroid \\
\hline 1 & 3 & $2 *$ & $7 \dagger$ & $9+$ \\
\hline
\end{tabular}

* One after second implant planned for total ablation
+ Two after second implant planned for total ablation.

Complications.-Thirty-nine implants were done on 28 patients, and complications were encountered in 11 patients. There were four instances of cerebrospinal-fluid leak, of which two subsided spontaneously; in the other two a stainless-steel screw was inserted in the hole in the fossa wall, which was effective in one, while the other finally required the surgical insertion of a muscle strip to seal the hole. Three patients developed meningitis, and five sustained pituitary abscesses. In two of these patients there had been a C.S.F. nasal drip, and it seems possible that some at least of the other cases developed their infection as sequelae to C.S.F. leaks which were not recognized. In one patient the pituitary infection proved fatal because of delayed treatment of the meningitis, but in the others it rapidly subsided after treatment with antibiotics. It 
has proved necessary to continue the antibiotics for several months after the initial infection to avoid a relapse. There were two patients who developed visual complications; one was a woman who had severe pituitary infection following a second implant and developed blindness of one eye, which began nine months after operation. The other woman was found to have a cyst, but was nevertheless satisfactorily implanted, with a good regression of her acromegaly; 15 months later she developed bitemporal hemianopia. Both these patients were operated upon by Mr. M. Falconer, who found large empty sellae with numerous adhesions, and the optic chiasmas and optic nerves were found pulled into the sellae.

Four patients developed diabetes insipidus, for which they required treatment with Pitressin; it was transient in three and permanent in one.

\section{Discussion}

It was our aim to give a sufficient dose of irradiation to the pituitary to produce a satisfactory remission of the disease, without producing hypopituitarism or endangering surrounding structures. The first objective has on the whole been attained; considerable and often striking remission of the disease usually followed the implant, and even some regression of bony acromegaly has been seen. On the other hand, hypopituitarism has not always been avoided, and some operative complications have followed. We hope that the present improved technique will lessen these disadvantages. The main hazard is that of either C.S.F. rhinorrhoea or infection, which we hope to minimize in future by using higher dosage ${ }^{90} \mathrm{Y}$ implants, which may be self-sterilizing, and pre-operative nasal antibacterial sprays. Two patients developed late visual-field defects. Each was somewhat unusual ; one had had a serious infection of the pituitary, and in the other a pituitary cyst had been encountered at operation. Perhaps these circumstances were responsible for the tethering of the surrounding structures to the pituitary surface, and so for their later subsidence into the fossa, resulting in damage to the optic nerve or chiasma by traction. While pituitary function was usually preserved after the implant so that no replacement therapy was needed, such therapy was required in seven patients, either because a second implant was planned to destroy the pituitary or because of post-operative pituitary infections, and in two others because hypopituitarism developed two to three years after the implant.

Alternative methods of treatment may be compared. Striking improvement of acromegaly, with regression of the acromegalic facies, has been reported following a maximal dosage of conventional deep $x$-ray therapy (Johnsen, 1952), but this is rare. Reports of early surgical series, in which the procedure was restricted to removal of as much of the tumour as possible rather than total hypophysectomy (Henderson, 1939 ; Bakay, 1950), showed that striking remission of the disease was unusual, and in one of the series (Henderson, 1939) 20 out of 59 patients died of recurrence of their disease. Hamberger et al. (1959) reported significant regressions in all of their 10 patients who were subjected to total hypophysectomy via the transantrosphenoidal route without serious morbidity, and good results were also obtained by Ray (1960). On the other hand, surgical mortality has been quite high in some series of operations for pituitary tumour ; for instance, it was $16.4 \%$ in the series of Decker and Lauter (1960), and even higher figures were quoted in their review; in addition, such total hypo- physectomy necessarily makes the patient steroid- and thyroid-dependent.

The report of Lawrence et al. (1962) indicated that highenergy heavy-particle irradiation can also produce striking remissions in acromegaly ; they obtained good results in 5 out of 15 patients, but three developed visual impairment. Pituitary implantation of ${ }^{90} \mathrm{Y}$ seeds by Molinatti et al. (1962), using seeds of much higher activity than those used in the present study, led to improvement in acromegalic features in 13 out of 16 patients, and the two patients with field defects were relieved of these. Cortisone therapy was required in only one case. They had no instances of pituitary infection, while in the present series 8 out of 39 implants were followed by this complication. Perhaps the more active ${ }^{90} \mathrm{Y}$ rods exert a stronger self-sterilizing effect than those used in the present series.

It would seem that a higher dose of irradiation than that used for most of this series is required for optimal results. We are now using implants of ${ }^{90} \mathrm{Y}$ alone, planned to give a peripheral dose of 20,000 rads. The limiting factor to the dosage which can be used will probably be the incidence of hypopituitarism rather than irradiation damage to surrounding structures.

\section{Summary}

Twenty-two patients with acromegaly have been assessed after therapeutic partial pituitary ablation by implantation of ${ }^{198} \mathrm{Au},{ }^{90} \mathrm{Y}$, or both. Nine of the patients required second implants. The response to the treatment was classed as satisfactory in 13, partial in six, and not improved in three. Other pituitary function was not impaired in 13 patients; corticosteroid and/or thyroxine dependency developed in nine, of whom two had had deliberate total pituitary destruction by a second implant and five a pituitary abscess. One patient developed permanent diabetes insipidus. Complications from a total of 39 implants (in 28 patients) consisted of eight cases of pituitary infection (one fatal), and four cerebrospinal fluid leaks (all recovered, one requiring surgical repair). Two patients developed late visual-field defects associated with retraction of the optic nerves into large empty sellae.

We would like to express our thanks to the Department of Medica Physics, Hammersmith Hospital, for their invaluable assistance in calculating the dosimetry of implants.

\section{REFERENCES}

Bakay, L. (1950). f. Neurosurg., 7, 240.

Bishop, P. M. F., and Briggs, J. H. (1958). Lancet, 1, 735

Buys, N. S., and Kerns, T. C., jun. (1957). Amer. f. Ophthal., 44, 483. Decker, K., and Lauter, H. (1960). Germ. med. Mith., 5, 265.

Fraser, R., and Joplin, G. F. (1961). In Modern Trends in Endocrinology, 2nd series, edited by $\mathrm{H}$. Gardiner-Hill, p. 69. Butterworth, London Opie, L. H., and Rabinowitz, D. (1962). F. Endocr., 25, 299. Hamberger, C. A., Hammer, G., Norlén, G., and Sjögren, B. (1959). 7. clin. Endocr., 19, 1500 .

Henderson, W. R. (1939). Brit. F. Surg., 26, 811.

Honderson, W. R. (1939). Brit. F. Surg., 26, 811.

Joplin, G. F., Fraser, R., and Keeley, K. J. (1961a). Lancet, 2, 67.

Steiner, R., Laws, J., and Jones, E. (1961b). Ibid., 2, 1277.

Kelly, K. H., Felsted, E. T., Brown, R. F., Ortega, P., Bierman, H. R., Low-Beer, B. V. A., and Shimkin, M. B. (1951). F. nat. Cancer Inst. 11, 967.

Lawrence, J. H., Tobias, C. A., Born, J. L., Sangalli, Fr., Carlson, R. A and Linfoot, J. H. (1962). Acta radiol.' (Stockh.), 58, 337.

Molinatti, G. M., Camanni, F., Massara, F., Olivetti, M., Pizzini, A., and Guiliani, G.'(1962). 7. clin. Endocr, $22,599$.

Ray, B. S. (1960). F. Neurosurg., 17, 1. 